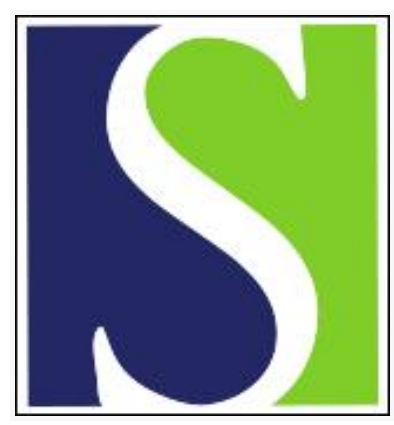

Scand J Work Environ Health 2004;30(5):339-349

https://doi.org/10.5271/sjweh.821

Issue date: Oct 2004

\title{
Working population health metrics
}

by Nurminen $\mathrm{M}$

Affiliation: Department of Epidemiology and Biostatistics, Finnish Insitute of Occupational Health, Topeliuksenkatu 41 a A, FI-00250 Helsinki, Finland. Markku.Nurminen@ttl.fi

Refers to the following text of the Journal: 1995;21(2):143-150

The following articles refer to this text: 2008;34(2):83-95;

2009;35(1):1-5

Key terms: demography; health metrics; health promotion; review; statistics; work ability; working population; worklife expectancy

This article in PubMed: www.ncbi.nlm.nih.gov/pubmed/15529797 


\title{
Working population health metrics
}

\author{
by Markku Nurminen, PhD ${ }^{1}$
}

\begin{abstract}
Nurminen M. Working population health metrics. Scand J Work Environ Health 2004;30(5):339-349.
This review is concerned with population health metrics that simultaneously consider information on mortality and nonfatal health outcomes as probabilistic measures representing the level of health in a working population. The optimal properties that such a measurement system should have are briefly discussed, and the merits and limitations of health expectancies are compared versus health gap measures. The conceptual basis of these measures are considered, especially with a view to health promotion. The application of worklife expectancies is illustrated with the data obtained from sequential surveys on the work ability status of aging Finnish municipal workers. In conclusion, the developed worklife expectancies are considered to be appropriate indicators for measuring the future duration of occupancy in a given state of work ability, and they should be preferred to alternative measures of population health in the context of occupational health.
\end{abstract}

Key terms demography, health promotion, review, statistics, work ability, worklife expectancy.

Summary measures of population health can be used for detecting differences (eg, between genders, between groups with different work abilities, etc), changes over time, or changes as a result of health promotion (1). The most precise and appropriate approach to monitoring changes in the health of working populations would be the longitudinal, detailed measurement of specific morbidity in cohort populations. Examples of specific morbidity measures include incidence rates of acute conditions, such as injuries or acute skin infections, and prevalence rates of chronic illness, such as chronic obstructive pulmonary disease and musculoskeletal disorders. Population health measures based on diagnostic category are highly informative in the search for disease determinants and prevention. An alternative approach would rely on the general measures of population health status. General measures have the advantage of capturing the impact of a wide range of illnesses in a population, and they are valuable in putting disease-specific information in perspective at the population level. Examples of general measures include measures of disability or perceived health status. The primary obstacle to the use of these measures is the requirement to obtain valid data from large-scale survey samples. Thus, as noted by van der Maas (2), "Ideally a summary measure has a wide range of applications, but inevitably there is a trade-off between the specificity of the information that is contained in the measure and its general applicability [p 55]".
Health expectancy is a generic term for population indicators that estimate the average time a person would expect to live in a defined state of health, provided that the prevailing patterns of mortality, morbidity, and disability continue to apply (3). Health expectancy is a valuable indicator of the appreciation of changes in the health states of the general population, and it can be used for allocating resources and evaluating the success of health policy programs (4). Early efforts to develop such measures were made by Chiang (5) and Sullivan (6). The International Network on Health Expectancy (Réseau sur l'espérance de vie en santé (REVES), Netsites: http:/ /www.revesnetwork.net/ and http://euroreves.ined.fr/ reves/) has furthered and developed the concept and methods of health-state measurement (7), both of which are now widely used at the national level and by the Organization for Economic Co-operation and Development to report on population health (8). The World Health Organization (WHO) has also recommended the use of health expectancy as a summary indicator of population health (9). This population health measure integrates information on mortality and health-related quality of life. Health expectancies are linked to the measurement of a particular health state or a set of states, and they focus on a person's perceived health and longterm illness (chronic disease, defect or injury).

Health-related quality of life is defined on a quantitative scale from 1 to 0 . The number of years of life lived in "perfect" health is given the value of unity, and the

1 Department of Epidemiology and Biostatistics, Finnish Institute of Occupational Health, Helsinki, Finland.

Correspondence to: Dr Markku Nurminen, Department of Epidemiology and Biostatistics, Finnish Institute of Occupational Health, Topeliuksenkatu 41 a A, FIN-00250 Helsinki, Finland. [E-mail: Markku.Nurminen@ttl.fi] 
valuation for the state of death is zero. These valuations imply that health levels lie on a continuum. A cynical person may criticize that it is difficult "... to apprehend the concept of health-related quality of life that is 'equivalent to death', and equally if its zero value actually is taken to characterize the health aspects of life post-mortem! [p 1060]" (10). At the other end of the health scale, WHO (11) defines health as a state of complete physical, mental, and social well-being and not merely as the absence of disease or infirmity. If this definition is taken to mean "perfect" health, then this lofty ideal should be linked to an operational measure.

\section{Measuring work ability and health status}

The work ability index developed by Tuomi et al (12) was contructed from the following seven items: subjective estimation of current work ability compared with the lifetime best, perceived work ability in relation to both physical and mental demands of work, number of diseases diagnosed by a physician, subjective estimation of work impairment due to disease, sickness absence during the past year, own prognosis of work ability after 2 years, and psychological resources. The index is a simple sum of the item scores, and it has a scale of values ranging from 49 to 7 . The scale can be transformed to run from 1 (full work ability) to 0 (unable to work). This distribution allows the classification of people according to the severity of their work disability (breaking up the continuum of work ability into polychotomous states). Interestingly, it would seem that the best predictors of future illness and loss of work ability would be the person's own assessment of his or her health and work capacity-better than any "objective" clinical examination. A poor work environment, bad occupational hygiene, a high level of work strain, a high risk of accidents, and poor work organization, all appeared to be negative predictive factors for maintaining health and work ability later on (13). Conversely, a wellfunctioning work organization, the support of superiors, the promotion of the worker's health and functional capacity, the promotion of professional competence, and physical activity seem to further the preservation of work ability (13). The index, which was developed for measuring health in relation to the quality of worklife in Finland, has been tested in several other countries as well \{eg, Brazil (14), Germany (15), Lithuania [Pajarskiene B, Jankauskas R. Occupational stress and changes in work ability index among employees in five enterprises of Lithuania (abstract). European Centre for Health, Safety and the Environment (ECOHSE) 2000 Symposium, Kaunas, Lithuania, 4-7 October 2000. Netsite: www.gla.ac.uk/ecohse/abstracts.html; accessed 3
November 2003], Portugal (16), and Sweden (17)\}. The self-assessment of health status has been validated using clinical methods (18). The results indicate that the questionnaire responses on health, work ability, and functional capacity related fairly well to the clinically assessed factors at the group level. However, work ability was not validated for psychological resources or for the physical and mental demands of work (Leena Eskelinen, personal communication). The concept of work ability is essentially bound to the societal and investigative context, and, therefore, it is not possible to completely validate the index. For example, as people approach retirement age, they tend to think less about retirement than do younger persons (19). For the self-assessment of retirement timing to be consistent in relation to individual characteristics, it should be anchored to the respondent's age. Moreover, some methodological issues still need to be rigorously examined; these issues pertain to reliability and item response scaling (20). Thus it can be questioned whether the index accurately measures work ability, however conceptually defined.

Self-reported measures of health status are based on people's perceptions and expectations of health. In addition, these perceptions and expectations vary with culture and community and are also likely to vary with time (21)_for example, as societies undergo epidemiologic transition (22) or as public health campaigns and legislative measures alter the community's awareness of health problems and attitudes towards health hazards (23). Murray \& Lopez (24) reviewed studies that suggested that there are significant cross-cultural differences between a self-report and an observation of disability and poor health. Thus, although indicators of health expectancy are potentially attractive for comparing the health of populations, considerable care must be taken to ensure their comparability across countries and cultures. Moreover, some epidemiologic questionnaire studies have shown a tendency to self-appraise health at a higher level than found in a clinical examination (25).

\section{Summary measures of population health}

Murray et al (26) proposed desirable properties that optimal summary measures should have for comparing the health of populations. The criteria are of the following type. If the severity of a given health state is worse than average, then the summary measure should also be worse if, say, everything else is the same. Such criteria were given specifically for measures of mortality, prevalence, incidence, remission, and severity of illness. For example, health expectancies based on prevalence data calculated using Sullivan's method fail the criterion for severity, whereas health expectancies based on transition rates meet 
the criterion. No summary measure satisfies simultaneously the criterion set for prevalence and incidence.

One can construct a summary measure that uses explicit weights to combine life expectancies into a single composite number for a set of discrete health states, indicating the expectation of years of "average" health state (in some sense). For example, the cost-effectiveness of health-care intervention has been assessed in terms of a gain in quality-adjusted life expectancy (QALE) (27-29). For the estimation, experts need to assign values for the years of life lived with disability and to calculate a weighted average over the years survived.

In worklife applications, one could compute a weighted measure of life expectancy, for example, with weights equal to the mean values of the work ability index. Such a measure could be termed work-ability-adjusted life expectancy (WALE) in analogy with the QALE. Therefore, for example, if a worker gains 5 years in a work ability state valued at 0.6 (on a scale of 1 to 0 ), he or she gains $5 \times 0.6=3$ WALE years. One can also consider an alternative measure of how many worklife years a person loses because of disability, compared with an ideal or "perfect" situation, in which there is no loss of functioning throughout a person's work career. In a similar manner, the difference between the qualityadjusted survival of a healthy person and that of a person with a particular disease measures the utility of health lost in contracting disease (30). This measure can be an efficient tool with which to supplement the primary indicators of health (ie, mortality and incidence rates). However, there may not be a compelling need for such a quantification of the data when the objective is priority setting for health intervention; simple summaries of epidemiologic data in terms of the number of years lost will ordinarily suffice in most applications encountered in occupational health research and policy making.

\section{Worklife expectancy}

Worklife expectancy, like health expectancy, is the future time that a person at a given age is expected to spend in employment. While it is a hypothetical construct that is not directly measured, it is an intuitive and broadly accessible concept. As such, it can provide the means for summarizing and comparing the health status of the employed population, as well as the means for monitoring time trends in occupational health. Summary measures for workyears can provide useful indicators for evaluating labor-force potential, as well as for evaluating the need for employer and pension plan accommodation (31). Although the calculation of worklife expectancy tables is complex (32-34), their wide use demonstrates that they are comprehensible. In the ap- proach adopted by Nurminen et al (35), worklife expectancies were estimated using a logistic regression model for multinomial probabilities of the health states of excellent, good, fair, and poor work ability. Work ability assessments were based on the index developed by Tuomi et al (12). These expectancies can be presented either as readily interpretable simple numerical summaries or charted as areas under a worklife survivor curve. Worklife expectancies have the advantage over other summary measures in that they are measured in units (expected years of worklife) that are meaningful to ordinary laypersons. Richards \& Abele (36) discussed traditional frequency-based methods for computing worklife expectancies in the context of forensic economics. In particular, interest can be focused on the gains in the probability of being employed, which is related to work ability and the expected duration of remaining worklife affected by occupational health care practices or worklife intervention. Measured together, these items provide useful information on population health, and they have the advantage of not assuming that the years of worklife gained are necessarily healthy years of life.

Worklife expectancies are formally defined in terms of worklife table probabilities (32). Thus they have a direct probabilistic interpretation in contrast to measures of longevity weighted by disability. Let $p(x, y)$ be the probability that a person aged $y$ years is employed if he or she had started work at the age of $x$ years. The worklife expectancy is then defined as (35):

$$
e(x)=1 / 2+\sum_{y=x+1}^{w} p(x, y)
$$

(equation 1)

where $w$ is the person's age in his or her last year of employment. In the computations it is assumed that the earliest commencing date is the middle of the entry year. The impact of the $1 / 2$ factor reduces the total worklife expectancy by 6 months. Note that $e(x)$ does not depend on the particular age structure of a population.

This measure of worklife expectancy can be expanded by basing it on the probability of occupancy in a given state of work ability. Let $p_{\mathrm{i}}(x, y)$ denote the probability that an individual known to be alive at age $x$ is in state $i$ (eg, excellent or good work ability, $i=1$; fair work ability, $i=2$; poor work ability, $i=3$; no longer working, $i=4$ ) at a subsequent age $y=x+1, x+2, \ldots$. The worklife expectancy of state $i$ is then defined as (35):

$$
e_{\mathrm{i}}(x)=\pi_{i}(x) / 2+\sum_{y=x+1}^{w} p_{i}(x, y)
$$

(equation 2)

where $\pi_{i}(x)$ is the prevalence of the alive state $i$ at age $x$. With the assumption of a regression model for $p_{i}(x$, $y$ ) and numbers for ages $x, e_{i}(x)$ can be computed numerically, either with the use of the aforementioned discrete 


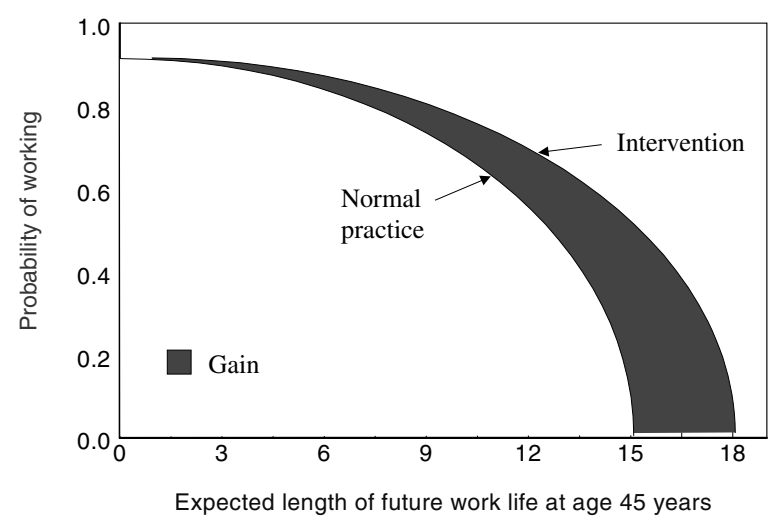

Figure 1. Probability of working and the expected length of future worklife gained for an aging worker via occupational health intervention. Modified from figure 4 in Williams (46).

approximation or as the following integral function:

$$
e_{\mathrm{i}}(x)=\int_{x}^{w} p_{\mathrm{i}}(\mathrm{z}) d z .
$$

(equation 3)

The $e_{i}(x)$ represents the area under the worklife survival curve from $x$ to $w$.

Figure 1 depicts a hypothetical worklife survival curve for a population that has undergone occupational health intervention (eg, via the promotion of work ability) as opposed to normal practice. Comparison of the profiles of the worklife survival curve gives an assessment of the effectiveness of the intervention in terms of a change in the evolution of the health of a working population. In figure $1, x=45$ years, and $w=45+18=63$ years is taken as the statutory retirement age. The effect is, for example, at the end of worklife (when the probability of work equals zero), assumed to be equivalent to an average gain of $18-15=3$ years in an aging worker's career.

Furthermore, if a person was in state $i$ at the start of follow-up, then the conditional worklife expectancy of state $j$, given initial state $i$ at age $x$, can be defined using the equation of Nurminen et al (37) (see the appendix):

$$
\begin{aligned}
& e_{i j}(x)=1 / 2+\sum_{y=x+1}^{w} p_{i j}(x, y), \text { for } j=i, i=1,2, \ldots, \\
& =\sum_{y=x+1}^{w} p_{i j}(x, y), \text { for } j \neq i,
\end{aligned}
$$

(equation 4)

where $p_{i j}$ is the transition probability from work ability state $i$ to state $j$. At any particular age, for example, a person can be classified as being in one of the following four states: having excellent or good work ability (state 1), having fair or poor work ability (state 2), being on a disability pension or deceased (state 3 ), and being retired on an old-age or similar pension (state 4). The $p_{i j}$ can be estimated by a multiple logistic regression model that can include age and time and the like as covariates. In the estimation of the transition probabilities, one assumes that the stochastic process that produced the aggegated data was a discrete time-nonhomogeneous Markov chain (38).

\section{Example: worklife expectancy of aging Finns}

As an illustration of the application of the methodology to the estimation of worklife expectancy, consider the study of aging Finns (35). This study appears to be the first to calculate cohort health expectancies for a real employed population. It estimated the future duration that a person aged 45 years or older would live in different states of health, provided that the prevailing patterns of mortality, morbidity, and disability remain unchanged. The data obtained from the questionnaire surveys conducted by the Finnish Institute of Occupational Health in 1981, 1985, and 1992 (39) among 6257 municipal workers were used for the estimation. The assessment of work ability was based on self-rated scoring (12). The probability of belonging to a work ability category was modeled by means of the marginal distribution of work ability estimated from the sequential crosssectional surveys of the worker cohort. Transition probabilities between different states of employment and health were also estimated (37). They were then used to compute the worklife expectancies. This study focused on the future occupation times in the different health and employment states conditional to a person's initial age and state of work ability. The secondary concern was with gender inequality in population health.

Consider a worker who enters employment at the age of 45 years; this person has, at the most, 17 or 18 years of remaining worklife before the statutory retirement age of 63 years. ${ }^{2}$ The study estimated that a male worker is an active employee for 11.5 years, and a female worker for 12.2 years, on the average (figure 2). The worklife expectancy was estimated to be 5.5 years for men with excellent or good work ability, 4.5 years for those with fair work ability, and 1.5 years for those with poor work ability. The worklife expectancies in the respective work ability classes for women were estimated to be longer: 5.6 (excellent or good), 5.0 (fair), and 1.6 (poor). In terms of effectiveness (10), the effect of a transition from the initial state of poor to good work ability was estimated to be, on the average, 4 years of gained active worklife for both the men and the women. This additive decomposition of health expectancies in relation to the specified levels of work ability is an appealing property of the measure of worklife expectancy. The decomposition is helpful in understanding at what stages changes in population health are occurring and quantifying the magnitude of those changes.

2 The Finnish data pertain to a period of 10 to 20 years ago when the official retirement age from municipal occupations ranged from 53 to 63 years. In 1981, $62 \%$ of municipal workers had a retirement age of 63 years, for $35 \%$ of the workers it was 58-62 years, and for only $3 \%$ it was lower than 58 years. Currently, the statutory retirement age for municipal workers varies and is between 63 and 65 years. For the purpose of this review, I have used a retirement age of 63 years because I was not aiming at comparing different occupational groups; instead my emphasis was on a comparison between groups with different work abilities. 


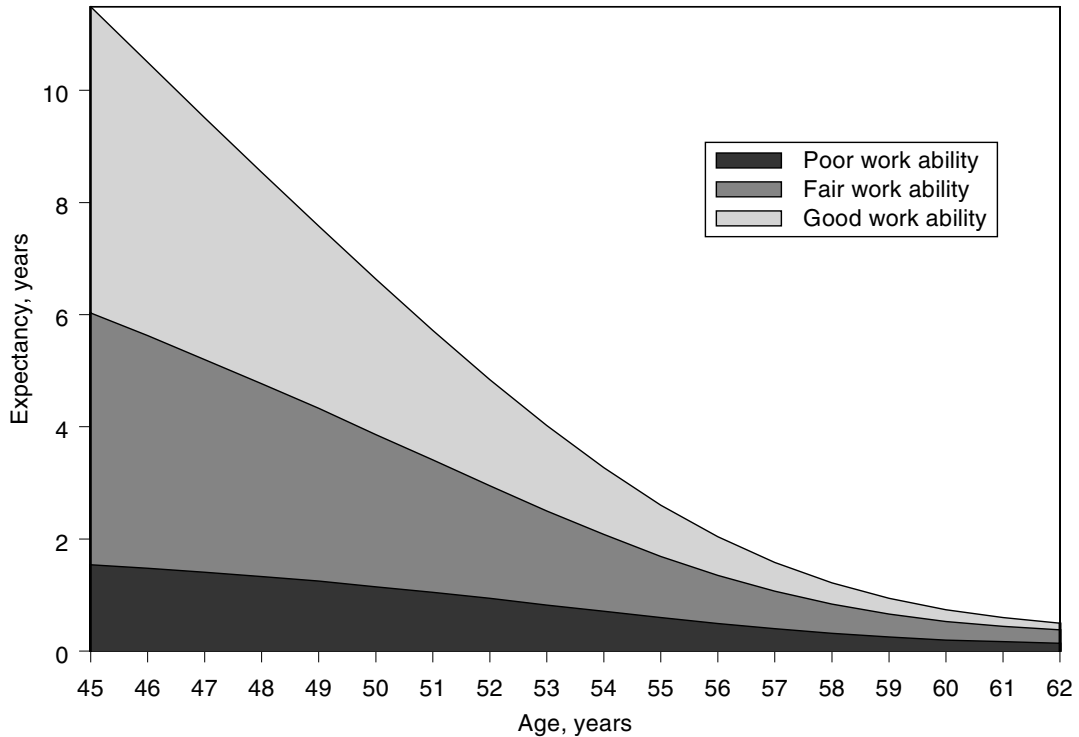

Figure 2. Worklife expectancy of Finnish male workers according to their work ability status and age. The worklife expectancies for poor work ability are first plotted along the age axis with the subsequent values for fair work ability and good work ability "stacked" on top of the previous ones. For example, at the age of 45 years, a male worker is expected to be actively employed 1.5 years with poor work ability, $4.5(=6.0$ $1.5)$ years with fair work ability, and 5.5 (= 11.5-6.0) years with good or excellent work ability. The worklife expectanies add up to $11.5(=5.5+4.5+1.5)$ years. (Data from the worklife expectancy project of the Finnish Institute of Occupational Health)
The study further estimated that, of the 60-year-old workers, both men and women, less than $30 \%$ remained actively engaged in worklife. This finding indicates that most municipal workers left worklife before the statutory retirement age of 63 years. A man ran a $43 \%$ risk of retiring prematurely on a disability pension; for a woman, the risk was only $26 \%$. A man's corresponding probability to retire on an old-age or similar pension was $34 \%$, whereas, for a woman, it was much greater, $59 \%$. A man's risk of dying before the age of 63 years was $6 \%$; for women the risk was $4 \%$. In general, men's death rate was two- to fourfold women's rate, and the rate was accentuated in the younger age groups. Figure 3 [de Finetti's (40) diagram ${ }^{3}$ ] illustrates the joint distribution of the probabilities of the work-health states for men aged 50-62 years.

The study demonstrates that the work ability of an aging Finnish worker deteriorates prematurely (ie, before the statutory retirement age), and this deterioration can lead to far-reaching socioeconomic consequences. Thus it is important to examine the development of work ability already before the age of 45 years, when it is still possible to intervene in the process by promoting work ability. Greater labor flexibility and concerted effort are needed to encourage higher labor-force participation among older workers, particularly skilled people. Especially aging male workers would need more flexibility than the present worktime arrangements. Free time is appreciated clearly more as one ages, and particularly men tend to retire early in order to gain time for their own activities. Older workers have the potential to make a continuing social and economic contribution to Finland. The extent of this contribution will depend on the

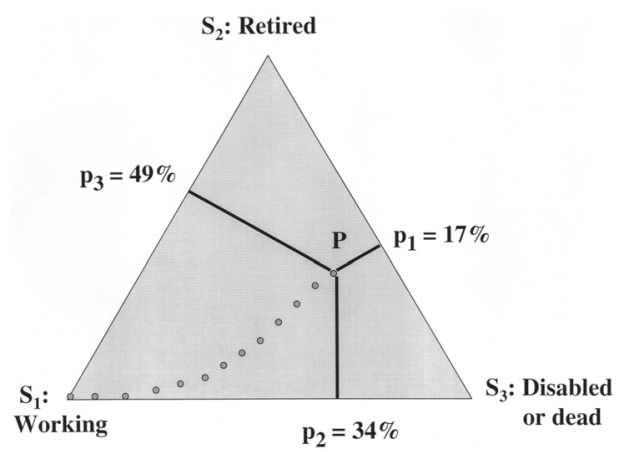

Age $\begin{array}{llllllll}50 & 52 & 54 & 56 & 58 & 60 & 62 & \text { years }\end{array}$

Figure 3. Probability distribution of work-activity states $\left(S_{1}=\mathrm{em}\right.$ ployed, $S_{2}=$ retired, $S_{3}=$ disabled or dead) for men represented by point $P$, from which the distance computed from vertex $S_{i}$ to the opposite side is $p_{i}(i=1,2,3)$. For example, the estimate for the probability of being employed was $p_{1}=17 \%$.

ability of older workers to continue to work, and their interest in doing so. It will also be influenced by the changing nature of work and the attitudes of employers towards the value of older workers. If the employment rate ${ }^{4}$ declines, this scenario entails risks because of the effects of population aging. The present working-age population, especially the large age cohorts born in 1945-1949 (relatively the largest in Europe), will be reaching retirement age in 2005-2014, as younger and smaller cohorts are joining the labor force. The inevitable consequence will be a

3 de Finetti's triangular diagram is interpreted mathematically as follows: Place a mass proportional to the prevalence $p_{i}$ of state $i=1,2,3$ at an angle of the equilateral triangle $\left(S_{1}, S_{2}, S_{3}\right)$ and compute the center of gravity of the three masses, $P$. Then the distance from $P$ to the side opposite vertex $S_{i}$ is $p_{i}$. In x-y plane geometry, the coordinates of $P$ are $\Sigma_{i} p_{i} x_{i}$ and $\Sigma_{i} p_{i} y_{i}$, where $x_{i}$ and $y_{i}$ are the cordinates of $S_{i}, i=1,2,3$. If the height of the triangle equals 1 , then point $P$ defines the probability distribution of the three states $\left(p_{1}, p_{2}, p_{3} ; p_{1}+p_{2}+p_{3}=1\right)$. The path formed by the age-specific points describes the stochastic process that generated the estimated probabilities.

4 Employment rate means the share of employed persons in the working-age population. The working-age population is traditionally defined as the 15 - to 75 -year-old population. In practice, the working-age population is often restricted to 15-64 years because the majority of persons older than 64 years in most developed countries are retired. Employed persons in Finland include all those who had worked at least 1 hour during the week that the Labour Force Survey was conducted by Statistics Finland. 
steady shrinkage of the working-age population starting in 2005. Hence Finland faces a future of dwindling numbers of employed persons, who will have to pay for the increased costs of the health care and social security of the expanding retired population. The young may resent the tax burden imposed on them to pay for the pensions and health expenditures of the elderly. Priority should be given to curbing the burden of taxation on the working population. On the other hand, there is a looming intergenerational conflict if baby-boomers must prepare themselves to give way economically to succeeding generations. It could be reasoned that the generations now approaching retirement age do not have an automatic right to expensive social welfare subsidized by younger workers.

The study concluded that worklife expectancy is an appropriate and readily interpretable measure to describe statistically the way in which a population's work capacity develops in different initial states and how it affects premature mortality, disability, and old-age retirement. Summary measures for worklife provide useful information for evaluating the labor force potential and the factors affecting retirement, as well as for assessing the need for a program to encourage employees to continue to work.

The defined measure of worklife expectancy has the distinct connotation that it allows the summary to be multivariate. In other words, the outcome parameter [eg, the logarithm of the ratio of the probability of state $i, p_{i}$ $(x, y)$, to the probability of the referent state] is expressed in terms of multiple covariates, $z_{1}, z_{2}$, etc, of a temporal, spatial, and socioeconomic nature. Greenland (41) has suggested that covariates may also represent alternative actions (or interventions). For example, $z_{1}$ could specify that the tax on tobacco is raised by $10 \%, 20 \%$, or $30 \%$, and $z_{2}$ could specify the options for lowering the tax on alcohol by 30\%, 40\%, or 50\% (eg, in Finland dictated by circumstances in the European Union). An analysis of worklife expectancy using a multivariate regression model enables one to capture the joint impact of several causes of work disability. With regards to tobacco smoking, for example, the analytical model could be used to assess the components of the legislation to determine how they affected the disease outcomes of interest (eg, lung cancer incidence or mortality from respiratory and cardiovascular diseases). The various components can be assessed within a comprehensive model that includes epidemiologic data, legislative data, economic variates (price and consumption data), sociodemographic variates, and program data (media campaigns). This multivariate framework can clarify what is captured and missed by any unidimensional measure of population health (41). Such a modeling exercise is planned for a time series of the entire Finnish employed population.

\section{Health gap measure}

The considerations of combining life expectancy and health-related quality of life into a single measure motivated an alternative method, described first in the World Development Report (42). It measures health gaps that quantify the difference between actual health and the norm for health (43). There are many ways to express health gaps. A popular measure is disability-adjusted life years (DALY), that is, a combination of the time lost due to premature mortality and the time lived with a disability, adjusted for the severity of the disability. This is a concept that has been used to measure the "global burden of disease" (44) and, subsequently, has been used in several studies on the national burden of disease. WHO publishes reports of the global and national "burden of disease" (45). The DALY has also been used as a tool for setting priorities in health policy, especially to guide the allocation of resources for health care intervention.

The proponents of the DALY suggest that it can be used for both purposes (24). In a critical appraisal of the DALY approach, Williams (46) stated that, although there is some useful information to be obtained from the present DALY procedure, it is not worth the cost and there are better strategies for monitoring population health and prioritizing health resources. He suggested that, "What we need to measure is what impact different interventions will have, not what impact different diseases have [p 2]". "Once this is done, things become much simpler, because we can concentrate on incremental changes and abandon the attempt to calculate comprehensive aggregates on a global basis [p 6]". Williams (46) concluded that the calculation of aggregate measures, which involve too many idiosyncratic elements to be capable of straightforward interpretation or application, is not feasible for solving health policy problems. Instead, what one needs to know is the marginal impact of different interventions on people's health. In response, Murray \& Lopez (47) noted that Williams' claim (ie, that summary measures of population health are irrelevant to policy formulation) is contradicted by the interest shown by many countries and international agencies, for example, WHO, in estimating these measures. In my opinion, it would seem to be an overcritical and one-sided stance to argue that only incremential changes through intervention, and not the level of population health, matter. Consider an analogous argument to employment. Would an economist conclude that the unemployment rate has no policy relevance and that only the costs arising from payments to the new unemployed workers and the number of new jobs created through government policies are informative? Moreover, Murray et al (48) denied that they have ever claimed that resources should be directed to health problems solely on the basis of their relative contributions to premature mortality and nonfatal health outcomes. Summary measures of population health can give useful information for debates on priorities for health action. 
In another critical review of the DALY, Anand \& Hanson (49) argued that the conceptual and technical basis of this new measure of disease burden is flawed. They also questioned the assumptions underlying the measure and its value judgments. In particular, they found that the implications of age weighting (reflecting the social value of people at different ages) and discounting (meaning that benefits are better when delivered sooner rather than later) to be unacceptable. Anand \& Hanson (49) also stated that allocating resources by aggregate DALY measures is inequitable because the information set for measuring the disease burden and allocating resources differ and the users of the DALY measure do not make this distinction. In defense of the DALY, Murray \& Acharya (50) maintained that these measures can guide policies towards delivering more cost-effective and equitable health care, within an information set comprising the health conditions of people differentiated solely by age and gender. According to their stance, the DALY measure is grounded on cogent economic and ethical principles and can guide decisions regarding heath policies.

In the application of the DALY approach, the particular health-state weights used to account for nonfatal health outcomes are derived with the use of the "person trade-off method". The question is "If you would have to choose between extending the life of 100 able-bodied persons versus the life of $100+x$ disabled persons, which number $x$ would make your choice indifferent?" The chosen number $x$ is then used to calculate disability weights that are supposed to quantify the relative severity of different states of disability. But, as pointed out by Williams (46), the answer to the question depends on both the valuation of health states and people's ethical concerns, which are difficult or impossible to quantify. Note that the method requires that there be more disabled persons than healthy persons (ie, $x>0$ ). Otherwise, if $x<0$, it would be implied that disabled persons are better than healthy persons, and this possibility is irrational according to the valuation of health states as adapted in the DALY approach.

In yet another criticism of the DALY measure, Lyttkens (51) went even further and claimed that the measure does not do what it purports (to measure population health) and concluded that its use in priority setting is ethically dubious (eg, in that it gives higher priority to prolonging the life of someone who is young and healthy compared with someone who is old and disabled). It would appear, however, that the DALY indicator has been more readily accepted than the more familiar and general concept of QALE. Obviously, the effect of intervention can be calculated either as an increase (gain) in the QALE or as a reduction (gap) in the DALY. It may be that the DALY has been advocated as a measurement instrument for preventive health care.
According to Lyttkens (51), this means that prioritizing concerns "statistical persons", and explicit prioritizing is thus less offensive in that context than when the QALE is measured for priority setting in the (palliative, therapeutic, or rehabilitative) health care of actual persons. There are also concerns about the use of the DALY to decide who gets the limited health funds available. While the DALY may indicate where problems exist (as do many other summary measures of population health), it has been argued that it does not give information on whether investing money in the health problem, for example, through intervention, will pay off (52). The procedure analogous to DALY in the context of work capacity would require the estimation, probably by subjective considerations, of factors affecting future work. This approach may be unavoidable in the field of forensic economics, but is perhaps best avoided in other contexts and, generally, when direct measures are more easily interpretable.

Originally, many mortality-gap measures were formulated in terms of the loss to a person. When aggregated to the level of a population, the implications of individual loss due to premature mortality have not always been appreciated (26). For example, Murray (53) has shown that, for many mortality-gap measures and health gaps, the implied target or the norm for population health may change as the mortality level changes, and it therefore makes direct comparisons between communities impossible. Indeed, as Murray et al (43) remarked, "The most fundamental conceptual question for developing health gap measures is the definition of the normative health function [p 984]". A population norm for an employed population would specify a reference healthy worklife expectancy, and the health gap would be calculated as a simple difference between the observed worklife expectancy and this reference. However, like health expectancy, this type of health gap is not easily decomposed into the contribution of different causes to give the total health gap for a population (48).

\section{Models of disablement}

Other critical points regarding health-gap measures include calculation methods and an array of conceptual issues regarding the definition, measurement, and valuation of health states. Although the World Development Report (42), which made use of the DALY, provided an extensive discussion on disability, disability as a concept was not defined. The definitional concern here has to do with the fundamental assumption about the nature of disability that underlies the DALY concept. The methodology makes the assumption that disability is a disease. The "medical" model of disablement views 
disability conceptually as a person's observable deviation from biomedical norms of structure or function that directly results from disease, trauma, or another condition of ill health $(54,55)$. The DALY method attempts to classify disability states based on the International Statistical Classification of Diseases (56) by grouping together a wide range of serious diseases according to their physical, sensory, intellectual, and emotional consequences. According to WHO (57), however, disease and disability are distinct concepts, which are to be viewed independently.

Years of life with a disability need not be viewed necessarily as years of life "lost" to disability, nor can they always correctly be described as years "burdened" by disease (58). A disabled person's lot in life can be considerably more productive if he or she has access to resources and technical aids that will allow more selfsufficiency. An aging, disability-free worker may have difficulties with memory, experience limitations in actively learning the use of new technologies, and participate in a limited way in areas of worklife that require teamwork. A worker of the same age with a disability may not be "handicapped" by such limitations.

Another problem with the DALY method is the assignment of a "reduced value" for lives lived with disability of physical functioning. The approach relied on the subjective assessment of medical experts to identify the major disabling sequelae for each of the 107 diseases and injuries and to attach weights to disability conditions according to severity. Unfortunately, this valuation of disability is strikingly at odds with the social, economic, and human rights gains that have been made by the disability community (58). Disabled people are not to be regarded as a net drain on society. What is called physical or mental disability is not simply an attribute of a person, but rather a complex combination of conditions, activities, and relationships. The WHO (59) classificatory instrument has endeavored to define disability more accurately by emphasizing the social context within which people live. The "social" model of disability, on the other hand, sees disability largely as a problem created by the social environment, whose management requires collective action at the level of society. To capture the integration of the various dimensions of functioning more comprehensively, a "biopsychosocial" model was developed by WHO (45). In this multidimensional approach, the different dimensions of functioning and disability are conceptualized simultaneously at biological, individual, and social levels. Thus it would appear that the focus has shifted away from the "medical" model to encompass wider realms. This shift may be a result of the fact that there is a need to develop the basic "medical" model; yet, an epidemiologist would be inclined to regard the "biopsychosocial" model conceptually as a modification of the former.
The DALY method is unable to address disability in a context beyond that of the individual. For example, using the "social" model for disability, an actively working university professor with a spinal cord injury resulting in paraplegia may prove far more productive, both scientifically, socially and economically, than his or her healthy colleague who engages exhaustively in extracurricular (eg, sports) activities during official workhours. A person's quality of life and achievements depend, to a large extent, on the sociocultural, legal, and economic ramifications of living with a disability (58). An identical disability for a poor worker living in an underdeveloped country and a wealthy professional living in a developed country might produce very different consequences. The latter person's need for assistance at home or at work may create jobs for some persons. In terms of the DALY, both persons could be equally burdensome medically to their societies. Yet, the real issues that affect their lives differentially are economic and social.

Finally, there is fear that a specific disease can be used as a basis in the DALY calculation to justify denial to disabled persons, not only of medical services, but of other resources from other areas society as well (58). For example, a person's impaired ability to walk resulting from dyskinetic cerebral palsy should not make him or her less worthy of an education or of being hired for work. Although the DALY indicator can help economists and decision makers distribute health services to the public benefit, it may also allow them to more easily justify the disfranchisement of a certain, marginal segment of the population of its right to health care.

\section{Concluding remarks}

The criticism referred to in this review was not presented with the intent of downplaying the efforts put forth by the health scientists who have developed summary measures of population health; on the contrary, the intention was to encourage further methodologic work on the measurement of work (dis)ability. The DALY and worklife expectancy measures belong to two different classes of indicators, and both are useful in different settings. In a recent review, Murray et al (26) examined a range of options for summarizing population health, and the main debates and challenges surrounding them. They concluded that, "Despite the extensive developmental agenda that remains, applications of summary measures cannot await the final resolution of all methodologic issues, so they should focus on those measures that satisfy as many basic criteria and desirable properties as possible [p 981]". In conclusion, I regard worklife expectancies as useful indicators for measuring the 
future duration of occupancy in given states of work ability and prefer them over alternative summary measures of population health in the context of occupational health.

\section{Acknowledgments}

I thank Leena Eskelinen and Sven Hernberg for their useful comments and Terttu Kaustia for the English language revision. The appendix is based on the notes of Professor R Heathcote.

\section{References}

1. Field MJ, Gold GM, editors. Summarizing population health: directions for the development and application of population metrics. Washington (DC): Institute of Medicine, National Academy Press; 1998.

2. van der Maas P. Application of summary measures of population health. In: Murray CJL, Salomon JA, Mathers CD, Lopez AD, editors. Summary measures of population health: concepts, ethics, measurement and application. Geneva: World Health Organization; 2002. p 53-60.

3. Mathers CD. Health expectancies: an overview and critical appraisal. In: Murray CJL, Salomon JA, Mathers CD, Lopez $\mathrm{AD}$, editors. Summary measures of population health: concepts, ethics, measurement and application. Geneva: World Health Organization; 2002. p 177-204.

4. Robine JM, Ritchie K. Healthy life expectancy, evaluation of global indicator of change in population health. BMJ 1991;302:357-60.

5. Chiang CL. An index of health: mathematical models. Washington (DC): National Center for Health Statistics; 1965. Vital and health statistics series 2, no 5.

6. Sullivan DF. A single index of mortality and morbidity. Health Serv Mental Health Adm Health Rep 1971;86:37454.

7. Mathers CD, Robine JM. Health expectancy indicators: a review of the work of REVES to date. In: Robine JM, Mathers CD, Bone RM, Romieu I, editors. Calculation of health expectancies, harmonization, consensus achieved and future perspectives: proceedings of the 6th international network on health expectancy and the disability process REVES; October 1992, Montpellier. Paris: John Libbey Eurotext; 1993.

8. Organisation for Economic Co-operation and Development (OECD). Eco-santé: OECD health database 1999. Paris: OECD; 1999.

9. deBruin A, Picavet HSJ, Nossikov A. Health interview surveys: toward international harmonization of methods and instruments. Copenhagen: World Health Organization Regional Office for Europe; 1996. WHO regional publications, European series, no 58.

10. Miettinen OS. The modern scientific physician, 5: the useful property of an intervention. CMAJ 2001;165:1059-60.

11. World Health Organization (WHO). Constitution. Geneva: WHO; 1948.

12. Tuomi K, Ilmarinen J, Jahkola A, Katajarinne L, Tulkki A.
Work ability index. 2nd edition. Helsinki: Finnish Institute of Occupational Health; 1998.

13. Tuomi K, Huuhtanen P, Nykyri E, Ilmarinen J. Promotion of work ability, the quality of work and retirement. Occup Med 2001;51:318-24.

14. Monteiro MS, Silveira DBB. A registered sickness absence among Brazilian aging health workers. In: Nygård $\mathrm{C}-\mathrm{H}$, Luopajärvi T, Lusa S, Leppänen M, editors. Promotion of health through ergonomic working and living conditions; outcomes and methods of research and practice: proceedings of the 33rd Annual Congress of the Nordic Ergonomics Society, 2-5 September 2001, Tampere, Finland. Tampere (Finland): University of Tampere, School of Public Health; 2001. Publications 7.

15. Tuomi K, Ilmarinen J, Jahkola A, Katajarinne L, Tulkki A. Arbeitsbeweltigungsindex: Schriftenreiche der Bundesanstalt für Arbeitsschutz und Arbeitsmedizin, Übersetzung - Ü14 [Work ability index: Federal Institute for Occupational Safety and Health, translation]. Dortmund (Germany): Bundesanstalt für Arbeitsschutz und Arbeitsmedizin; 2001.

16. da Silva CF, Silvério JMA, Sousa Nossa PNM, Lopes Rodrigues VJ, Sousa Pereira A, Ferreira Queirós AJ. Envelhecimento, ritmos biológicos e capacidade laboral—versão portuguesa do work ability index (WAI) [Aging, biological rhythms and working capacity-Portuguese version of the work ability index (WAI)]. Braga (Portugal): Instituto de Educação e Psicologia, Universidade do Minho; 2000. Rev Psicol Número 2-resumos.

17. Dallner M, Gamberale F, Olsson AM, Örelius D. Testning av ett samnordiskt frågeformular om psykologiska och sociala factorer i arbetslivet [Testing of a joint Nordic questionnaire on psychological and social factors in working life]. Solna (Sweden): Arbetslivsinstitutet; 1999. QPSNordic, Arbetslivsrapport 14.

18. Eskelinen L, Kohvakka A, Merisalo T, Hurri H, Wägar G. Relationship between the self-assessment and clinical assessment of health status and work ability. Scand J Work Environ Health 1991;17 Suppl 1:40-7.

19. Gould R. Eläkeajatukset: katsaus aiheeseen liittyviin tutkimustuloksiin [Retirement thoughts: review of research results related to the topic]. Helsinki: Eläketurvakeskus [Finnish Centre for Pensions]; 2001.

20. Bowling A. Measuring health: a review of quality of life measurement scales. Bristol (PA): Open University Press; 1993.

21. Mathers CD. Disability-free and handicap-free life expectancy in Australia 1981 and 1988. Canberra (Australia): Australian Institute of Health, AGPS; 1991. AIHW health differentials series, no 1 .

22. Johansson SR. The health transition: the cultural inflation of morbidity during the decline of mortality. Health Transition Rev 1991;1:39-68.

23. Heloma A. Impact and implementation of the Finnish Tobacco Act in workplaces. Helsinki: Finnish Institute of Occupational Health; 2003. People and Work Research Reports 57.

24. Murray CJL, Lopez AD, editors. The global burden of disease: global burden of disease and injury series, volume 1 . Harvard (MA): Harvard University Press, 1996.

25. Maddox GL, Douglass EB. Self-assessment of health: a longitudinal study of elderly subjects. J Health Soc Behav 1973;47:87-93.

26. Murray CJL, Salomon JA, Mathers C. A critical examination of summary measures of population health. In: Murray CJL, Salomon JA, Mathers CD, Lopez AD, editors. Summary 
measures of population health: concepts, ethics, measurement and application. Geneva: World Health Organization; 2000. p 13-40.

27. Fanshel S, Bush JW. A health status index and its applications to health services outcomes. Oper Res 1970;18:102165.

28. Gold MR, Siegel JE, Russell LB, Weinstein MC, editors. Cost-effectiveness in health and medicine. Washington (DC): US Government Printing Office; 1994. p 107-30. Report no OTA-H-678.

29. Wilkins R, Adams OB. Quality-adjusted life expectancy: weighting of expected years in each state of health. In: Robine J-M, Blanchet M, Dowd JE, editors. Health expectancy. London: Her Majesty's Stationery Office; 1992. OPCS studies on medical and population subjects, no 54.

30. Wang J-D. Basic principles and practical applications of epidemiological research. Singapore: World Scientist Press; 2002.

31. Crimmins EM. Health expectancies: what can we expect from summary indicators of population health? In: Murray CJL, Salomon JA, Mathers CD, Lopez AD, editors. Summary measures of population health: concepts, ethics, measurement and application. Geneva: World Health Organization, 2002: 213-9.

32. Hoem JM. A Markov chain model of working life tables. Scand Actuarial J 1977;77:1-20.

33. Ciecka J, Donley T, Goldman J. A Markov process model of work-life expectancies based on labor market activity in 1992-93. J Leg Econ 2000;9:33-68.

34. Millimet D L, Nieswiadomy M, Ryu H, Slottje D. Estimating worklife expectancy: an econometric approach. J Econometrics 2003;113:83-113.

35. Nurminen MM, Heathcote CR, Davis BA. Estimating marginal cohort working life expectancies from sequential crosssectional survey data. J Off Stat 2004;3:1-23.

36. Richards H, Abele JR. Life and worklife expectancies. Tucson (AZ): Lawers and Judges Publishing Company, Inc; 1999.

37. Nurminen MM, Heathcote CR, Davis BA. Estimating conditional working life expectancies from aggregate cohort data. Internet J Epidemiol. Available from: http://www.ispub.com/ ostia/index.php?xmlFilePath=journals/ije/front.xml. In press.

38. Chiang CL. Introduction to stochastic processes in biostatistics. New York (NY): John Wiley \& Sons, Inc; 1968.

39. Tuomi K, editor. Eleven-year follow-up of aging workers. Scand J Work Environ Health 1997;23 Suppl 1:1-71.

40. Rossi C. Bruno de Finetti: the mathematician, the statistician, the economist, the forerunner. Stat Med 2001;20:3651-66.

41. Greenland S. Causality theory for policy uses of epidemiological data. In: Murray CJL, Salomon JA, Mathers CD, Lopez AD, editors. Summary measures of population health: concepts, ethics, measurement and application. Geneva: World Health Organization; 2002:291-301.

42. Oxford University Press. World development report: investing in health. New York (NY): Oxford University Press; 1993.

43. Murray CJL, Salomon JA, Mathers CD, Lopez AD. Health gaps: an overview and critical appraisal. In: Murray, CJL, Salomon JA, Mathers CD, Lopez AD, editors. Summary measures of population health. concepts, ethics, measurement and application. Geneva: World Health Organization; 2002. p 233-44.

44. Murray CJL, Lopez AD. The global burden of disease (published on behalf of the World health Organization and the World Bank). Cambridge (MA): Harvard School of Public Health; 1996.

45. World Health Organization (WHO). The international classification of impairments, disabilities and participation (ICIDH2). Geneva: WHO; 1997.

46. Williams A. Calculating the global burden of disease: time for a strategic reappraisal? Health Econ 1999;8:1-8.

47. Murray CJL, Lopez AD. Progress and directions in refining the global burden of disease approach: a response to Williams. Health Econ 2000;9:69-82.

48. Murray CJL, Salomon JA, Mathers CD, Lopez AD. Summary measures of population health: conclusions and recommendations. In: Murray CJL, Salomon JA, Mathers CD, Lopez AD, editors. Summary measures of population health. concepts, ethics, measurement and application. Geneva: World Health Organization; 2002. p 732-56.

49. Anand S, Hanson K. Disability-adjusted life years: a critical review. J Health Econ 1997;16:685-702.

50. Murray CJ, Acharya AK. Understanding DALYs (disabilityadjusted life years). J Health Econ 1997;16:703-30.

51. Lyttkens $\mathrm{CH}$. Time to disable DALYs? on the use of DALYs in health policy. Scand Work Pap Econ 2001;11. (Available at: http://swopec.hhs.se; accessed 3 November 2003.)

52. Mooney G, Irwig L, Leeder S. Priority setting in health care: unburdening from the burden of disease. Aust N Z J Public Health 1997;21:680-1.

53. Murray CJL. Rethinking DALYs. In: Murray CJL, Lopez $\mathrm{AD}$, editors. The global burden of disease: a comprehensive assessment of mortality and disability from disease, injuries, and risk factors in 1990 and projected to 2020: the global burden of disease and injury. Cambridge (MA): Harvard School of Public Health on behalf of WHO; 1996.

54. Boorse C. Health as a theoretical concept. Philos Sci 1977;44:542-73.

55. Bickenbach JE, Chatterji S, Badley EM, Ustun TB. Models of disablement, universalism and the international classification of diseases, disabilities and handicaps. Soc Sci Med 1999;48:1173-87.

56. World Health Organization (WHO). ICD-10: international statistical classification of diseases and health related problems, the tenth revision, volumes 1-3. Geneva: WHO; 1992.

57. World Health Organization (WHO). The world health report 1999: making a difference. Geneva: WHO, 1999.

58. Groce NE, Chamie M, Me A. Measuring the quality of life: rethinking the World Bank's disability adjusted life years. Disability World 2000;3(June-July). (Available at: http:// Www.disabilityworld.org/June-July2000/International/ DALY.html; accessed 3 November 2003).

59. World Health Organization (WHO). The international classification of impairments, disabilities and handicaps (ICIDH). Geneva: WHO, 1980.

Received for publication: 3 November 2003 


\section{Appendix}

\section{Estimation of worklife expectancies}

Consider the analysis of cohort data when the numbers are reasonably large, as in a multistate life table. Worklife expectancies or occupation times $e_{i j}(x)$ of state $j$ following the passage from state $i$ at age $x$ can be estimated from the transition probabilities, so the main problem is estimating the latter. Let the multistate transition probabilities be defined as $p_{i j}(x, y)=\operatorname{Pr}\{X(y)=j \mid X(x)$ $=i\}, x<y$, where, $X(x)$, with the given sequence of values of $x$, is the underlying discrete-time stochastic process that generated the observed data, with state space $\{1, \ldots, a, a+1, \ldots, a+b\}$ in which $1, \ldots, a$ label initial or nonabsorbing states (eg, conditions of health or employment) and $a+1, \ldots, a+b$ label states that are assumed to be terminal or absorbing (eg, death from different causes). For the derivation, the transition probabilities are parameterized as log-partial odds: the probability of a transition to another state divided by the probability of no transition [Davis et al (1), equation 1.1] $\theta_{i j}(x)=$ $\log \left\{p_{i j}(x, y) / p_{i i}(x, y)\right\}$ for $j=1, \ldots, i-1, i+1, \ldots, a+b ; i=1$, $2, \ldots, a(j \neq i)$. This parametrization is convenient for deriving the asymptotic Gaussian distribution of statistic $\widetilde{\theta}_{i j}$. Data are assumed to be available in the form of numbers of transitions for a cohort of $n(0)$ members at the start of the follow-up $(y=0)$. That is, one must be able to observe realizations of random variables $\tilde{n}_{i j}(x, y)$, that is, the number of the members of the cohort who are in state $i$ at $x$ and in state $j$ at age $y, x<y$, for a sequence of $x$ values.

Consider the special case of the following four states: state $1=$ working; state $2=$ on disability pension; state $3=$ on old-age pension; state $4=$ deceased. If states 2, 3 and 4 are terminal (or "absorbing", that is, there are transitions from these states), $a=1, b=3$. For the method to be applicable, a number of tables must be constructed for both genders and for persons of different initial ages. An application then proceeds to the regression modeling of the $3 \times 1$ data vector of the $\log$ partial odds as

$$
\widetilde{\Theta}(x)=\left(\begin{array}{l}
\log \left\{\tilde{\mathrm{n}}_{12}(x, x+1) / \tilde{\mathrm{n}}_{11}(x, x+1)\right\} \\
\log \left\{\tilde{\mathrm{n}}_{13}(x, x+1) / \tilde{\mathrm{n}}_{11}(x, x+1)\right\} \\
\log \left\{\tilde{\mathrm{n}}_{14}(x, x+1) / \tilde{\mathrm{n}}_{11}(x, x+1)\right\}
\end{array}\right)
$$

For the estimation of the Markov chain, the asymptotic distribution of $\widetilde{\Theta}(x)$ must be found. Since the transition probabilities sum up to the marginal probability,

$$
p_{1}=\sum_{j=1}^{4} p_{1 j}
$$

the likelihood function for $\Theta$ is of the form

$$
L\left(\tilde{\mathrm{n}}_{1 j} ; \Theta\right) \propto \prod_{j=2}^{4} p_{1 j} \tilde{n}_{1 j}\left(1-\sum_{j=2}^{4} p_{1 j}\right)^{\tilde{n}_{11}} .
$$

The Fisher information matrix is $\mathrm{I}(\Theta)=\left\{-E\left(\partial^{2} \log L(\Theta) /\right.\right.$ $\left.\left.\partial \Theta^{2}\right)\right\}$. Direct computation, with $p_{1 j}=p_{1 j}(x, x+1)$, yields

$$
I(\Theta)=n(0) p_{1}(x)\left(\begin{array}{ccc}
p_{12}\left(1-p_{12}\right) & -p_{12} p_{13} & -p_{12} p_{14} \\
-p_{12} p_{13} & p_{13}\left(1-p_{13}\right) & -p_{13} p_{14} \\
-p_{12} p_{14} & -p_{13} p_{14} & p_{14}\left(1-p_{14}\right)
\end{array}\right)
$$

This multinomial form is due to the Markov assumption. The asymptotic variance-covariance matrix of $\Theta$ is obtained by inversion as follows:

$$
\begin{aligned}
& V(x)=I(\Theta)^{-1} \\
& =\left\{n(0) p_{1}(x)\right\}^{-1}\left(\begin{array}{ccc}
p_{12}^{-1}+p_{11}^{-1} & p_{11}^{-1} & p_{11}^{-1} \\
p_{11}^{-1} & p_{13}^{-1}+p_{13}^{-1} & p_{11}^{-1} \\
p_{11}^{-1} & p_{11}^{-1} & p_{14}^{-1}+p_{11}^{-1}
\end{array}\right)
\end{aligned}
$$

The multiplier $n(0) p_{1}(x)=n_{1}(x)$ can be estimated by the corresponding empirical quantity $\tilde{n}_{1}(x)$ and $p_{1 j}(x, x+1)$ by $\tilde{n}_{1 j}(x, x+1) / \tilde{n}_{11}(x, x+1)$.

The parametrized vector of partial odds can be expressed in terms of a regression model: $\Theta(x)=Z(x)^{\prime} \beta$, where $Z(x)$ is a known vector depending on age $x$ and possibly other covariates, such as time and socioeconomic indicators. The likelihood equation to be minimized for obtaining an estimator of $\beta$, given in Davis et al (1, equation 3.3), is $L(\beta)=\sum_{\mathrm{x}}\left\{\left(\widetilde{\Theta}(x)-Z(x)^{\prime} \beta\right\}^{\prime} I(\Theta)\right.$ $\left\{\widetilde{\Theta}(x)-Z(x)^{\prime} \beta\right\}$. The transition probabilities are then estimated from

$$
p_{11}=\left[1+\sum_{j=2}^{4} \exp \left(\theta_{1 j}\right)\right]^{-1}
$$

and $p_{1 j}=p_{11} \exp \left(\theta_{1 j}\right)$, for $j=2,3,4$. Finally, the worklife expectancies can then be estimated from

$$
e_{1 j}(x)=1 / 2+\sum_{y=x+1}^{\mathrm{w}} p_{i j}(x, y) .
$$

The factor $1 / 2$ arises because it is assumed that the entry to worklife occurs in the middle of the initial year.

\section{Reference}

1. Davis BA, Heathcote CR, O'Neill TJ. Estimating and interpolating a Markov chain from aggregate data. Biometrika 2002;89:95-110. 